\title{
An Investigation of Mn-Ce-Based Conversion Coating on LZ91 Magnesium Alloy
}

\author{
Shun-Yi Jian $^{1, *}$, Ko-Lun Chang ${ }^{2}$ \\ ${ }^{1}$ Department of Chemical \& Materials Engineering, Chung Cheng Institute of Technology, National \\ Defense University, Dasi, Taoyuan 335, Taiwan, ROC \\ ${ }^{2}$ National Synchrotron Radiation Research Center, 101 Hsin-Ann Road, Hsinchu 30076, Taiwan, ROC \\ *E-mail: ftvko@yahoo.com.tw
}

doi: $10.20964 / 2018.08 .69$

Received: 18 April 2018 / Accepted: 12 June 2018 / Published: 5 July 2018

\begin{abstract}
Most of the magnesium alloys are relatively reactive and tend to suffer corrosion. Consequently, surface modifications are performed to enhance the corrosion resistance and paint adhesion of the base magnesium alloys. This work discuss with the non-chromate conversion coating on LZ91 magnesium alloy. The conversion coating treatment is conducted in an acidic cerium/permanganate solution with adding the different acidity regulators. These additives can adjust the $\mathrm{pH}$ value of the solution and influence the formation of anti-corrosion coatings on LZ91 substrate. The microstructure and composition of the conversion coating are characterized using SEM, EDS and cross-sectional TEM. The potentiodynamic polarization test, electrochemical impedance spectroscopy and salt spray test results show that the corrosion resistance of LZ91 alloy is markedly improved by the acidic cerium/permanganate conversion coating. The corrosion protection efficiency is related with the acidity regulator in the conversion solution. The film thickness also depends upon the acidity regulator used. Besides, micro-cracks are more obvious on the coating formed in the phosphoric acid bath. Therefore, the coating formed in the sulfuric acid bath does provide the LZ91 plate better corrosion protection when compared to the coating formed in the phosphoric acid bath.
\end{abstract}

Keywords: LZ91 Magnesium alloy; Conversion coating; Corrosion resistance; EIS; Microstructure

\section{$\underline{\text { FULL TEXT }}$}

(C) 2018 The Authors. Published by ESG (www.electrochemsci.org). This article is an open access article distributed under the terms and conditions of the Creative Commons Attribution license (http://creativecommons.org/licenses/by/4.0/). 